\title{
Editorial
}

\section{Introduction to the topical issue on Social Value of Materials}

The Anthroposphere and the Biosphere interact in many complex ways and this creates intense activity in many disciplines, from political science to industrial ecology and Climate Science to the Technology of $\mathrm{CO}_{2}$ emission mitigation, not to forget worldwide grand challenges that international bodies and national governments are trying to reign in, with other stakeholders like NGOs bringing in their contributions.

Apart from the growing importance of the issue due to population growth, economic globalization and urbanization at the grand scale of most of the world, this also raises methodological issues, interdisciplinary by nature, which require cooperation among the various scientific disciplines that tackle them. This very cooperation, among fields which have been driven by their own internal logics, is a special challenge.

Materials have been playing a special role in the way society and the economy operate, especially structural materials such as metals, concrete, glass, polymers and elastomers, wood and other bio-sourced materials, new materials like carbons, etc. which are the stuff of which all artefacts of the anthroposphere are made, and which also make the tools and machines from which these artefacts are manufactured, built or produced. This deep interconnection between society and materials has been at play ever since mankind emerged as a special mammal in the evolution of species. It is constantly renewed, revisited, reengineered and this has been going on for the last million of years!

Structural Materials have long been aware of their special role and thus of their responsibility to help the various fields establish fruitful methodological dialog and to work towards an integration of approaches, in a broad and pragmatic way.

This has given rise to an initiative called SOVAMAT, for SOcial VAlue of MATerials, a name chosen to mix words that do not necessary go together in usual circles (www. sovamat.com). This Initiative has been fostering research and progress in interdisciplinary methodological cooperation and proposing research projects for public funding at EU level for example.

The SOVAMAT Community meets once a year in a series of seminars called Society \& Materials (SAM) organized by ArcelorMittal, Academic Institutions that hosts the event and other stakeholders. Six meetings have been organized since 2007 and the next one will take place in Aix-la-Chapelle, Germany, on 25 and 26 April, 2013.

The present issue of Revue de Métallurgie publishes 11 selected and reviewed articles from the past seminars. It is organized around 5 themes: (1) an introduction explains the issues addressed by the SOVAMAT Initiative; (2) a section is devoted to significant advances in methodologies, including New Metrics, the Graal of SOVAMAT, dynamic MFA and a novel way of calculating the carbon footprint at the stage of the cradle rather than at emission points; (3) a section is devoted to the criticality of material supply, focusing on methodology and on the special case of lithium; (4) a section focuses on ecodesign of processes, centered on recycling, by-product management and integrated steel mill production; (5) finally, a section focuses on ecodesign of products, with a paper on reuse of a complex good 
(a shipping container) and another one on the subtle interaction between material design and standardization to meet society's needs.

These are limited but typical examples of issues addressed in SAM seminars.

The Guest Editor

Jean-Pierre Birat

ARCELORMITTAL, chairman of the SOVAMAT Initiative and of the SAM seminars 